ISSN: $2637-4692$

\title{
Why are Children Afraid of Dental Work?
}

\author{
Karimi M* \\ Internal Auditor \& Documentations at Apple Dental Clinic, Iran \\ Received: 監 May 21, 2018; Published: 眥 June 05, 2018 \\ *Corresponding author: Karimi M, Internal Auditor \& Documentations at Apple Dental Clinic, Iran
}

\begin{abstract}
For most children, dentist's offices always remind them a horrible environment. Going to the dentist, make children associate the ideas of a dental injection or tooth extraction in their imagination. To eliminate this fear, a series of strategies, methods and solutions is recommended. Several of these methods are innovative solutions which are applied in Apple Dental Clinic. Many factors may contribute in reducing the kid's anxiety. Child's preparation, parent's fear, Calling dentist as a kind friend, creating a stress-free environment, early age dental examination, having a good explanations for child curiosity, reducing the stress during injecting, avoiding using certain words, dental instruments and rewarding the patient play significant factors in child's fear. With using these models, fear reduction can be felt in children during the dental procedures. The strategies in this article have been well explained.
\end{abstract}

Keywords: Dental fear; Pain; Injection; Drill voices; Dental materials; Dental staff; Stress-free environment; Dental setting

\section{Opinion}

Dental clinic is one of the places when children usually are entering it, they make excuses and fuss about it; or sometimes resist seriously. For many children going to the dentist, it might be a dark and frightening event in their life. However, with use of the different methods, an expert dentist can convert that place to a happy space for children's curiosity to learn and gain experiences. To improve children's oral health care, it is better to be examined twice a year at an early age. Many factors are involved. For examples, injection, dental setting and environment, dental materials, drill voices, being unprepared by parents, dental staff, socioeconomic factors, bad dental experiences, and so on, have a direct impact in the creation of children's dental fear. As a general dentist who is working in the field of pediatric dentistry more than 20 years, these fear factors can be easily reduced or even in some cases completely can be eliminated by use of different methods, solutions or strategies. A numbers of important factors and their solutions are pointed below.

\section{Child's Preparation by Parents}

Parents can purchase books and educational software which is designed for children in simple language to familiar them with the concepts and practices of dentistry. In these books and educational CDs, the dental settings, dental instruments and equipments, dental procedures, dentist, dental staff and their duties are explained simply. The role of parents in this stage is very critical. Parents can be a good role model. They should just explain some simple points to their children. Parents try not to give additional explanations about their children's dental work. They should not act beyond what they know because it makes giving false information to the children which causes misconceptions to be formed in their minds. Therefore, it is wise to let the dentist to give necessary explanations to the children.

\section{Parent's Dental Fear}

Unfortunately, it has been observed that children's dental fear is due to the transformation of parents fear to their children in many cases. Prior to starting the first session, it is advisable the parents inform the dentist about any bitter dental experience if they may have had in the past [1]. If one of the parents had dental fear or bad dental experience before, it has been advised the other parent accompany the patient to the room. Children can easily feel their parents discomfort and anxiety about dentistry that is why parents should be cautious about their acts [2]. Some of the children behave normally when their parents do not present in the exam or treatment rooms. It will be wise, parents who visit the dentist, should keep their anxiety to themselves so that avoid passing their fears to their children.

\section{Portraying the Dentist as a Kind and Loving Person}

This factor is one of the factors that parents play an important role on. It is the responsibility of parents to call the dentist a "Good Guy". Unfortunately, some parents or relatives of kids when they 
talk about dental works in the presence of children, they create a monster from a dentist. This changes the mentality of child toward the dentist. Therefore, kids go to the dentist with more fear and anxiety. At this time, they have a different perspective about dentist's character. To break this taboo, the dentist should give the child a "Reward Certificate" after finishing any dental work. This will gain the trust of the child and create close relationship between them. The child would feel the dentist as a close friend. They would like to call his dentist "Uncle Doctor" so that they simply would enter the treatment room without accompanying parents in the later sessions. Ask them what they like to be called; by first name or nickname. When you call them by nickname, it makes them feel more comfortable with you.

To show the true character of a "Good Dentist", ask your patient to bring a nice drawing for the next visit. To demonstrate the value of his work, hang his/her painting on the wall of your office. It gives them a true self confidence. That enterprise is the responsibilities of parents to remember kids, the dentist is always a "Good Friend" and "Loving Person" .However, our colleagues must keep in their mind that only with smile, kindness and creating a pleasant atmosphere in exam room and treatment room, a positive result can be reached.

\section{Create a Tranquil and Stress-Free Environment}

The important part of a dental office that can have positive effects on reducing stress and anxiety of children is the Reception Area. Personnel behavior attracts the attention of children. Happy and smiling faces could be the first effective step to reduce children's stress. Dental environment should be a happy and comfortable place for children [3-5]. If there is an enjoyable atmosphere in the waiting room, children and their parents will feel comfortable on their arrival time. Smiling faces, greeting secretary, decoration setting, lightning and decorations in the rooms, all in a comforting environment, play an important role in establishing effective communications. In addition, Playing movies and cartoons for children, playing light music and letting children play in the games room before the treatment, have a significant effect in reducing of dental fears, anxiety and children's stress. Children should be examined in a special room examination by the dentist. The exam room should be separated from the treatment room. The examination room and treatment room to some extent in terms of instrumental layout and decoration arrangement should be different. In the examination room, we have to try to create a stressfree space where the child would feel more comfortable.

First, instead of wearing a white coat, the colored clothing or clothing with children's favorite cartoon scheme should be used. Wearing a colored mask face with cartoon drawing on it may help. Second, the walls of the examination room should be in bright colors and decorated with special posters for kids. Third, near the dental chair, there should be an oral hygiene kits including: baby doll tooth brush, children's toothpaste and a dent form.
Fourth, on the dental chair, devices such as kid's dental turbines, kid's hand pieces with rubber tip on it, and small monitors to be installed. By doing this strategy, you can prepare a good background for children to familiar with the environment and some of the dental instruments.

\section{Starting Dental Examination at Early Age}

Keep in your mind the first visit of the child is the most important one. The child should have a positive experience at the dentist at early age. This might have a good influence on him to not develop an ongoing fear of the other oral health care provider. The first dental examination should be done between the eruption of the first tooth and age of $1[6,7]$. If visiting the dentist happens at age of 1 , it might cut down a little of child's fear of the dentist. In his practice, the dentist can use the dental chair as a means of play during dental examination. When the kid seats on the chair, the dentist could tell him you are going up and down with an especial elevator. In another way, by putting him on supine position or moving the dental chair in back and forth direction, the kid should be told you are going to play see-saw game.

During the dental examination, it is always better to use pink, purple and red mirrors for girls, and blue, yellow and green mirrors for boys. Sometimes even let them to choose their favorite colored mirror. After selecting, start counting their teeth with a dental explorer. At the end, return back their mirrors. Using these methods, gain the patient's trust to the dentist, and they feel more comfortable. The first session is assigned only to diagnose and evaluate the oral health of the child and his/her individual character. In first visit, no dental treatment is recommended. After finishing the examination, our colleagues should give the child a reward such as a sticker with prints of doll pictures on it.

\section{Giving Simple Explanation}

If the child is curious and has questions, the first appointment is the best time to answer the questions briefly so that there is no doubt left whatsoever [8]. By drawing pictures, making models or even showing dental instruments the child patient can be introduced to applications of these devices. In Apple Dental Clinic, a unique name is given to each device. For example, a number of them are listed below. It is simply named a dental explorer as (instrument for counting teeth), turbines as (electric water sprayer), hand piece with a brush attached to it as (electric toothbrush), dental chair as (elevator), and suction as (vacuum cleaner), Furthermore, if a child has any questions, our colleagues can briefly demonstrate the procedure in simple language on the teeth models or small dolls.

\section{Second Appointment}

An issue which is very important is that simple dental works such as fissure sealants and fluoride therapy should be performed in this session. Explaining the correct way of tooth brushing of children to their parents is recommended. This appointment is 
the most important one for both child patient and dentist. Thus, because this is the first work on the child, it has been suggested that one of the parents be present in the treatment room so that it reinforces the child encouragement [9-11]. But parents should note that the best person who can manage his child is an expert dentist. Therefore, it is better not interfere with his work. For further encouragement of the child, giving small prizes like dolls, stickers for boys and girls, and stationary toys after finishing the second session can be a positive reinforcement [12].

\section{Injection Time}

This period of time is the most difficult one that a dentist is facing Children injections is one of the most stressful time for any dentist, but with a simple method, the procedure can be facilitated for both patient and dentist. When a child is seated on the dental chair, the dental assistant is holding patient's hand and tries to gently caress his hand. At the same time, the dentist slowly moves back the chair and holds gently patient's shoulder to feel more comfortable and relaxed so that he does not have fear of falling out of the chair on the floor. Before the injection, the dentist pretends playing see-saw game by moving the chair to back and forth position. To start the injection, our colleagues should always use the method of "Gels and Drops". Before starting, they might leave the choice of anesthetic taste to their patients. Girls prefer to select strawberries or cherries flavors but boys most likely go with pineapple or banana flavors.

First, numb the injection area with a cotton swab dipped into the local anesthetic gel. Then, tell the patient you are going to use a few drops of anesthetic to numb his gum. After that, with guarding hands in front of his face, ask patient to close his eyes so the drops don't fall down in his eyes. Then, your assistant should hold the empty bottle of drop near the injection site. While you do the injection very slowly, the assistant began counting out loud up to 10 . At the same time, ask the patient to start counting with his fingers. This distracting technique always works. With this trick, the child has not seen the syringe, and counting loud would make him to focus on his counting. Hence, he would believe that instead of injection, your assistant has applied the anesthetic drops. This trick makes him more willing to continue his treatment for the next session. In Apple Dental Clinic, many pediatric patients have come in tears and fears but have left the office with happy smiling faces. In case of difficulty in managing the pediatric patient, the dentist may use two common types of sedation which are Nitrous Oxide or oral sedative such as Valium $[13,14]$.

\section{Watch your Words}

Children are very sensitive to the use of certain words. When they hear them, they may overreact and agitate so their fears and anxiety would be doubled. During the dental procedures, avoid using words such as: pain, blood and injection, tooth extraction, surge, suturing and so on. When using words, try to replace them by those words which you can specifically costume design for children. For example, during the application of Acid $-\mathrm{H}$, if the patient feels that the injection would be performed, inject a little amount of the material on your gloves to show there is nothing to be afraid of. Tell him, this is a blue gel which makes your teeth whiter and shinier. You may name the forceps as means of measuring tooth mobility when you plan to extract his teeth. With your own creativities, you can encourage the patient to continue his/her dental procedure in the next sessions. Please note to start dental works like you are playing a game. For instance, after the injection, spray some water on the patient's hand. Kids love their childish games.

\section{The Sounds of Turbines and Hand Pieces}

One of the annoying problems for children during the dental procedures is the vibration and sounds of turbines, hand pieces and suction. Before starting the work, it is better these devices and their uses to be simply explained to the children. Sometimes telling a story or a diary, showing a cartoon movie or engaging the kid in a conversation can be used as a mean to drawing attention away from the dental procedures. In addition, singing children songs or playing a video song on the monitor in front of the patient, can relax and decrease the patient agitation.

\section{Childish Fantasies and Misconceptions}

Children most often analyze the dentist dressing, his talking, gestures and behaviors in their mind. As a result, it is plausible when speaking; avoid certain words that may increase patient's anxiety. They sometimes go beyond their childish imagination. Negative thoughts can worsen the child anxiety which may increase unexpectedly. Many times it has been observed when children see a sharp instrument during the dental procedures, they experience sever anxiety and agitation, and react surprisingly. Unfortunately, children at an early age when they see a sharp dental instrument, they think that is the terrifying dental syringe. This issue should be considered by our colleagues to prepare the patient by different approaches. Another important point is that some parents when their child is doing something wrong or disobeys them, they threat to take them to the doctor's office to have an injection. In fact, due to the narrow mindedness of some parents, this misconception forms in the child's imagination, going to the doctor is a kind of punishment for him/her. In another words, he thinks he is going to the dentist just to be punished not for having a dental treatment.

Negative mentality about dentistry may be created in many ways. In the most situations, it could happen when people talk in the presence of children about unpleasant dental experiences with their dentist. In fact, in these cases, the responsibilities of the dentist are very serious and effective so that he has to be able to trim and clean these misconceptions from child's mind. A dentist must have in his mind to refrain posting posters, pictures or drawings in his office that can create negative feelings in children. For instance, posters from business entities about periodontal diseases or maxillofacial surgery posters on the office walls, definitely causes inner fear in the child. Of course, this is more applied for general dentist offices. 


\section{Conclusion}

Children have fear of the dentist due to a number of factors. These important issues can be found in parent's fear, the dental environment, screeching sound of the functional devices, and children misconceptions resulted from close relative talks. As far as possible, we have to reduce negative feeling of kids toward the dentistry which in this case, both parents an dentist have great responsibilities. For this reason, it has been suggested that children should be familiar with dental environment at the early age. To end the fear of children, it is recommended to spend the first session only with the assessment and examination of the patient, and thereby create a mutual trust between them. In the next appointment, the dentist can use different techniques to calm the anxious patient. An expert and experienced dentist will know how to cope with kids fear and anxiety.

\section{References}

1. Baier K, Milgrom P, Russell S, Mancl L, Yoshida T (2004) Children's fear and behavior in private pediatric dentistry practices. Pediatr Dent 26(4): 316-321.

2. Klingberg G, Berggren U (1992) Dental problem behaviors in children of parents with severe dental fear. Sewed Dent J 16(1-2): 27-32.

3. Zhou Y, Cameron E, Forbes, G, Humphris G (2011) Systematic view of the effect of dental staff behavior on child dental patient anxiety and behavior. Patient Educ Couns 85(1): 4-13.

4. Sheller B (2004) Challenges of managing child behavior in the $21^{\text {s }}$ century dental setting. Pediatr Dent 26(2): 111-113.
5. Wright GZ, Stigers JI (2011) Nonpharmacologic management of children's behaviors. In: Dean JA, Avery DR, Mc-Donald RE, (Eds); McDonald and Avery's Dentistry for the Child and Adolescent. ( $9^{\text {th }}$ Edn); Maryland Heights, Mo: Mosby-Elsevier pp. 27-40.

6. (2013) Your child's first dental visit, PDF from American Dental Association.

7. Your child first visit (to the dentist), Canadian Dental Association.

8. Law CS, Blain S (2003) Approaching the pediatric dental patient: A review of nonpharmacologic behavior management strategies. J Calif Dent Assoc 31(9): 703-713.

9. Sheller B (2004) Challenges of managing child behavior in the $21^{\text {st }}$ century dental setting. Pediatric Dent 26(2): 111-113.

10. Pinkham JR (1991) An analysis of the phenomenon of in-creased parental participation during the child's dental experience. J Dent Child 58(6): 458-463.

11. Shroff S, Hughes C, Mobley C (2015) Attitudes and preferences of parents about being present in the dental operatory. Pediatric Dent 37(1): 51-55.

12. (2014) Guideline on Behavioral Guidance for the Pediatric Dental Patient, Reference Manual, American Academy of Pediatric Dentistry 37(6): 184.

13. Nathan JE (1989) Management of the difficult child: A survey of pediatric dentists' use of restraints, sedation, and general anesthesia. J Dent Child 54(4): 291-301.

14. AL Hallonsten, B Jensen, M Raadal, J Veerkamp, MT Hosey, et al. (2007) EAPD Guidelines on Sedation in Pediatric Dentistry.
This work is licensed under Creative Commons Attribution 4.0 License

To Submit Your Article Click Here: Submit Article

DOI: 10.32474/MADOHC.2018.02.000141

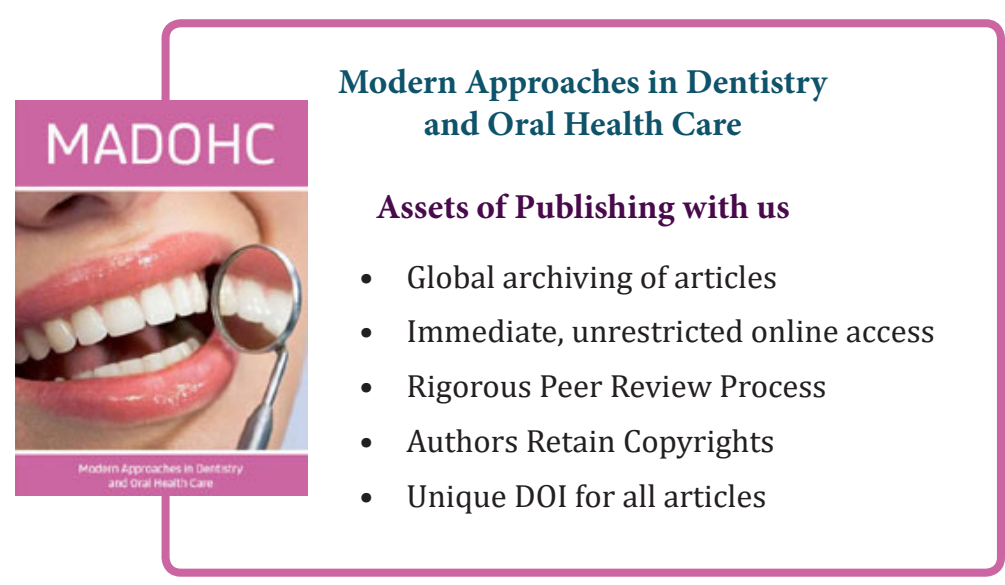

